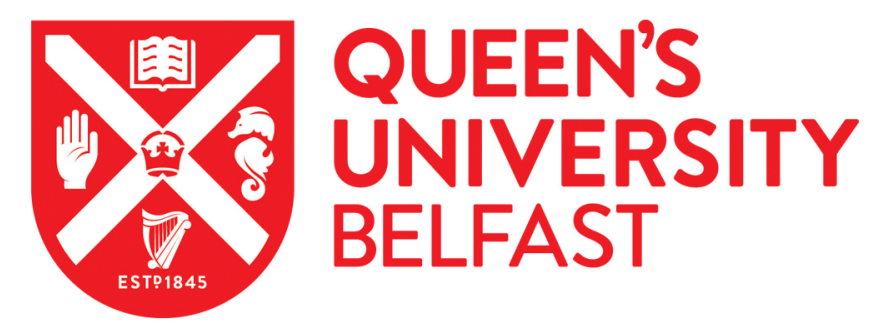

\title{
A field experiment on a steel Gerber-truss bridge for damage detection utilizing vehicle-induced vibrations
}

Kim, C. W., Chang, K. C., Kitauchi, S., \& McGetrick, P. J. (2016). A field experiment on a steel Gerber-truss bridge for damage detection utilizing vehicle-induced vibrations. Structural Health Monitoring, 15(2), 174-192. https://doi.org/10.1177/1475921715627506

Published in:

Structural Health Monitoring

Document Version:

Peer reviewed version

Queen's University Belfast - Research Portal:

Link to publication record in Queen's University Belfast Research Portal

Publisher rights

(C) 2016 The Authors.

\section{General rights}

Copyright for the publications made accessible via the Queen's University Belfast Research Portal is retained by the author(s) and / or other copyright owners and it is a condition of accessing these publications that users recognise and abide by the legal requirements associated with these rights.

Take down policy

The Research Portal is Queen's institutional repository that provides access to Queen's research output. Every effort has been made to ensure that content in the Research Portal does not infringe any person's rights, or applicable UK laws. If you discover content in the Research Portal that you believe breaches copyright or violates any law, please contact openaccess@qub.ac.uk. 


\title{
A Field Experiment on a Steel Gerber-Truss Bridge for Damage Detection Utilizing Vehicle-induced Vibrations
}

\author{
Chul-Woo Kim ${ }^{1)}$, K.C. Chang ${ }^{2)}$, Sotaro Kitauchi ${ }^{3)}$ and Patrick J. McGetrick ${ }^{4)}$ \\ ${ }^{1-3)}$ Department of Civil and Earth Resources Engineering, Graduate School of Engineering, \\ Kyoto University, Kyoto 615-8540, Japan \\ 4) School of Planning, Architecture and Civil Engineering, Queen's University Belfast, Belfast \\ BT9 5AG, United Kingdom
}

\begin{abstract}
A field experiment was conducted on a real continuous steel Gerber-truss bridge with artificial damage applied. This paper summarizes the results of the experiment for bridge damage detection utilizing traffic-induced vibrations. It investigates the sensitivities of a number of quantities to bridge damage including: the identified modal parameters and their statistical patterns, Nair's damage indicator (NDI) and its statistical pattern, and different sets of measurement points. The modal parameters are identified by autoregressive (AR) time-series models. The decision on bridge health condition is made and the sensitivity of variables is evaluated with the aid of the Mahalanobis-Taguchi system (MTS), a multivariate pattern-recognition tool. Several observations are made as follows. For the modal parameters, although bridge damage detection can be achieved by performing MTS on certain modal parameters of certain sets of measurement points, difficulties were faced in subjective selection of meaningful bridge modes and low sensitivity of the statistical pattern of modal parameters to damage. For NDI, bridge damage detection could be achieved by performing MTS on NDIs of most sets of measurement points. As a damage indicator, NDI was superior to modal parameters. Three main advantages were observed; it doesn't require any subjective decision in calculating NDI thus potential human errors can be prevented and an automatic detection task can be achieved, its statistical pattern has high sensitivity to damage, and finally, it is flexible regarding the choice of sets of measurement points.
\end{abstract}

Keywords: autoregressive model, bridge damage detection, field experiment, modal analysis, pattern recognition, vibration-based structural health monitoring.

1)Professor, corresponding author: kim.chulwoo.5u@kyoto-u.ac.jp; ${ }^{2)}$ lecturer; ${ }^{3)}$ graduate student; ${ }^{4}$ lecturer. 


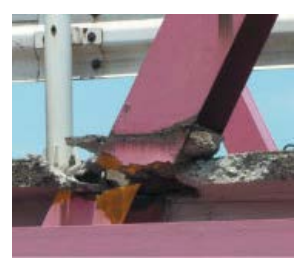

Fig. 1 Damage observed in a truss member due to corrosion. (adopted from [2])

\section{Introduction}

The collapse of the I-35W Mississippi River Bridge in Minneapolis, Minnesota, USA on August 1, 2007, was an unprecedented shock to the civil engineering community [1]. After the event, damage in members of steel truss bridges was also discovered during bridge inspections in Japan (see Fig. 1 [2]). In the aftermath of these events, maintaining and improving civil infrastructure including bridge structures have become keen technical issues, since any light structural damage or defects in a bridge can potentially result in fatal consequences. An effective maintenance strategy always relies on prompt and accurate decisions being made on the structural health condition. Structural health monitoring (SHM) using vibration data is one of the developing technologies for screening structural health condition [3, 4]. Most precedent studies on vibration-based SHM specifically examine the change in modal parameters of structures [5-16], based on a fundamental concept that the modal parameters are functions of a structure's physical properties and thus may vary due to a change in the physical properties, such as reduced stiffness due to damage. Application of the concept and techniques of vibration-based SHM to bridge structures, or simply referred to as vibration-based bridge health monitoring (BHM), has also resulted in a great amount of studies aiming to maintain bridge safety [11, 15-20]. A major task in BHM is to utilize any effective technique to detect the existence, and ideally the location and magnitude also, of damage when it appears.

For investigating the effectiveness of BHM techniques, field experiments on real bridges are important and of high reference value because they are conducted in an environment that is most similar to those within which the BHM systems will be operated. Such environments are generally not as well-controlled as those in numerical simulations and laboratories. However, most existing studies examine these BHM techniques by means of numerical simulations and laboratory experiments $[16,17,19,20]$, while still relatively few studies report their practical validity for real bridges, which are likely to be subject to budget limitations and service conditions that prevent relevant authorities from granting permission to apply damage to the bridge. Despite these 
limitations, a bridge owner permitted a field experiment to be conducted on a continuous steel Gerber-truss bridge in Japan with artificial damage applied, referred to as the field damage experiment hereafter. More details about the experiment are given in Section 2.

In the field experiment, how to excite the bridge economically, reliably and rapidly is an important technical issue. Ambient vibration induced by wind, ambient ground vibrations and daily traffic is one general excitation source. For small- and medium-span bridges like the experiment bridge in this study, which form the major portion of bridge infrastructure, wind and ambient ground vibrations are usually too small in magnitude to excite the bridges. On the other hand, daily traffic becomes dominant $[19,21]$. In this study, a passing truck serves to excite the bridge and the truck-induced bridge vibrations are recorded for further analysis.

The modal parameters of bridges, i.e. modal frequencies, damping ratios and mode shapes, and their derivatives, are often used to detect bridge damage. In many studies, the modal parameters are identified utilizing a linear time-series model $[11,15,16]$. Since the 1970s, the use of state-space models for modal-parameter identification in the time domain has been increasing and it has also yielded new approaches. Gersch et al. [22], for example, use the time series of an autoregressive moving average (ARMA) process to describe the random response of a vibrating structure subjected to white-noise excitations. Shinozuka et al. [23] present a second-order ARMA model to represent a vibrating structure in order to identify the structural parameters directly. Hoshiya and Saito [24] treat the parameters to be identified as additional state variables in the state vector using an extended Kalman filter. However, in identifying modal parameter using a time-series model, there is an unavoidable difficulty: the determination of physically meaningful modal parameters. A time-series model for bridge vibration responses usually comprises more terms, usually higher-order, than true structural terms, and thus yields spurious parameters unrelated to the true structural ones. Although the optimal order can be evaluated by certain existing criteria, it offers no clue in choosing physically meaningful modal parameters from spurious ones and therefore subjective judgment is usually required. Such a difficulty is discussed further in Section 4.1. Despite the difficulty, the modal parameters, identified with subjective judgment, are examined to determine if they are qualified to indicate bridge damage. In view of the above difficulty, an alternative damage indicator proposed by Nair et al. [25] is also examined in this study, considering the fact that it is simply composed of AR coefficients and thus free of modal-parameter identification. This indicator (hereafter referred to as Nair's damage indicator, NDI) has been verified to be sensitive to bridge damage in laboratory experimental studies [20, 26] but not yet in field experimental studies.

Mahalanobis-Taguchi system (MTS) [27-29], a multivariate pattern-recognition tool, is adopted to assist in making a decision on the bridge health condition. In the MTS approach, several 
observations of suitable variables gathered for the healthy condition are taken as a reference group and the Mahalanobis distance (MD) is taken to measure the degree of abnormality of individual candidate observations (probably in the damaged condition). In the experiment presented in this study, several runs of each test were carried out for healthy (or reference) and damage conditions respectively, each with several vibration responses measured from a set of sensors. Considering the modal parameters or NDI, identified from a single vibration response, either can be a variable and each test run provides an observation for MTS. In this study, the sensitivities of different properties and sets of variables to the bridge damage are investigated.

As mentioned previously, a field experiment was conducted on a real continuous steel Gerber-truss bridge with artificial damage applied. The objective of this paper is to summarize the results of the experiment for bridge damage detection utilizing traffic-induced vibrations and to investigate the sensitivities to bridge damage of: the identified modal parameters and their statistical patterns, NDI and its statistical pattern and different sets of measurement points. The modal parameters are identified by AR time-series models, which are briefly described along with the definition of NDI in Section 3, following the introduction of the experiment in Section 2. The decision on the bridge health condition is made and the damage sensitivity of variables is evaluated with the aid of MTS, whose algorithm is also given in Section 3. In Section 4, the identified modal parameters, NDI, and the sensitivities of the former two variables and different sensor sets to the bridge damage are presented, followed by several concluding remarks regarding the implication and limitation of the damage detection technique in practical applications.

(a)

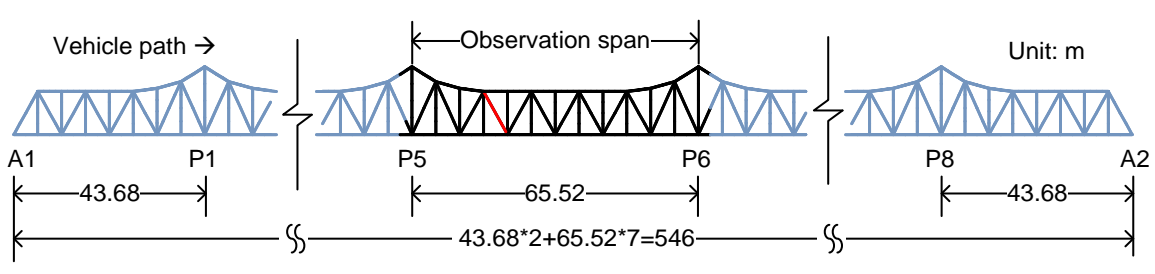

(b)

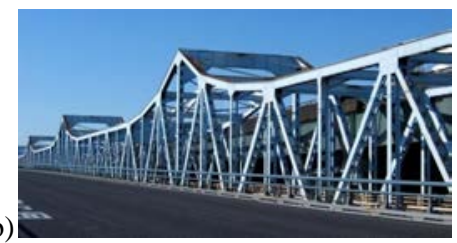

Fig. 2 Experiment bridge: (a) elevation view; (b) photo. 


\section{Field Experiment}

\subsection{Experiment Bridge and Artificial Damage}

The experiment bridge was a continuous steel Gerber-truss bridge, as shown in Fig. 2. The bridge comprises 9 spans, among which the 6th span, i.e. P5-P6 span, is selected as the test span. It was about $65.5 \mathrm{~m}$ in span length and $8.5 \mathrm{~m}$ in width. The test bridge was closed and provided for the damage experiment before being demolished.

In reference to damage previously observed in real steel truss bridges (see Fig. 1), a damage scenario consisting of a diagonal member fully severed was artificially applied in this study. The artificial damage was applied at the fourth diagonal member (marked in red in Fig. 2(a)). The cutting-off task was conducted as per the following procedure, along with many safety measures; Firstly, the damaged member was wrapped in a protection device (see Fig. 3(a)) assembled with brackets, jackets, steel bars and displacement restriction members to prevent any possible bridge collapse due to the abrupt release of tensile force of the damaged member. Then, via the jackets, a compressive force was applied which was equivalent to the design dead tensile force (about $658 \mathrm{kN}$ ) of the member. In this state, most of the tensile force of the member was expected to transfer to the protection device so that the member might hold little force before being cut off. Next, the member was fully severed using an Oxyacetylene cutting torch. Finally, the applied force of the protection device was steadily released. Figs. 3 (b) and (c) show photos of the element before and after it was severed. For differentiation, the bridge before the artificial damage is referred to as the intact bridge (even though it may not perfectly intact as in its newly-constructed status) and the bridge after the damage as the damaged bridge.
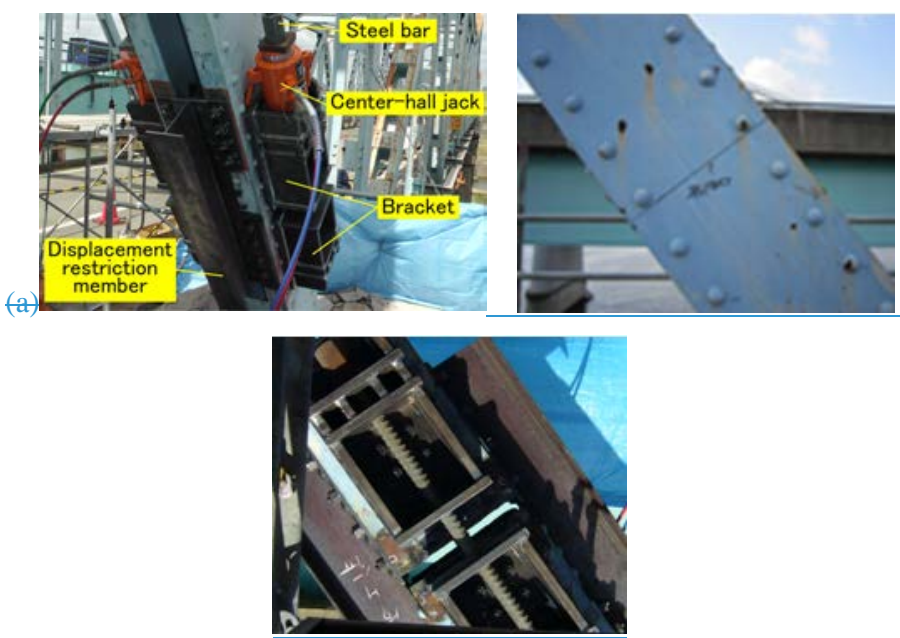

Formatted: Font color: Auto 
(a)

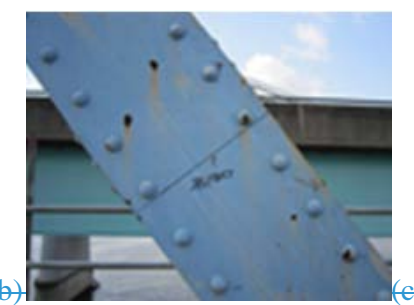

(b)

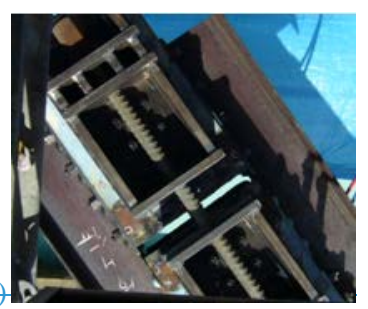

Fig. 3 Photo of damaged member: (a) protection device; (aㅁ) before and (b드) after the damage.
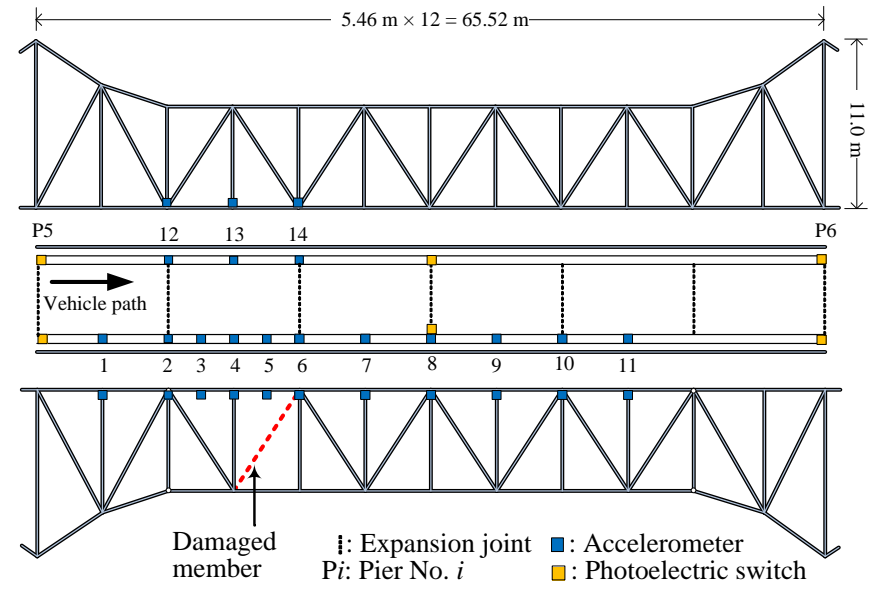

Fig. 4 Sensor layout.

\subsection{Sensor Layout}

Fourteen accelerometers (Types ARS-1 and ARH-A by Tokyo Sokki Kenkyujo Co., Ltd.) were installed on the bridge deck and wired to data loggers (Types DC104 and DC204 by Tokyo Sokki Kenkyujo Co., Ltd.). Eleven of those accelerometers were at the damage side and the other three at the opposite side, as shown in Fig. 4. All accelerometers were located on the deck near the truss nodes, except for the accelerometers No. 3 and 5 which were located on the deck near the midpoint of two adjacent nodes close to the damaged member instead of nodes in order to offer a denser sensor deployment to investigate whether it has advantages in damage detection/localization. Three pairs of photoelectric switches were installed, at the two endspans and the midspan, for the purpose of detecting the instants that the experiment vehicle entered, exited and reached the midspan of the bridge. The sampling rate for all accelerometers was $200 \mathrm{~Hz}$. Also, throughout this paper, the accelerometer ID is used to denote the measurement point ID. 


\subsection{Types of Test and Experiment Vehicle}

In the experiment, the bridge was excited by the passage of an experiment vehicle. The traffic was controlled to ensure that no other vehicle apart from the experiment vehicle was allowed. The experiment vehicle was a cargo truck of model LKG-CD5ZA, produced by UD Trucks Corp., as shown in Fig. 5. The experiment was conducted during daytime over two successive days. The experiment truck remained the same, but its total weight varied slightly from $253 \mathrm{kN}$ on the first day to $258 \mathrm{kN}$ on the second day (see Table 1 for more detailed weight allocations) due to the use of different piles of loading blocks. The temperature was not recorded, however no obvious variation in temperature was expected to occur due to the duration of the experiment on both days and the time of day it was carried out. The slight variations in total weight and weight allocation of the truck and that in the temperature can be reasonably neglected herein.

The truck passed the bridge with three planned constant speeds: 10, 20 and $40 \mathrm{~km} / \mathrm{hr}$ (designated as Cases V1, V2 and V3, respectively). The number of runs with respect to each speed is listed in Table 2. Another case, Case V4, is considered with all the runs in Cases V1 to V3, in order to present a more authentic case of normal traffic flow.

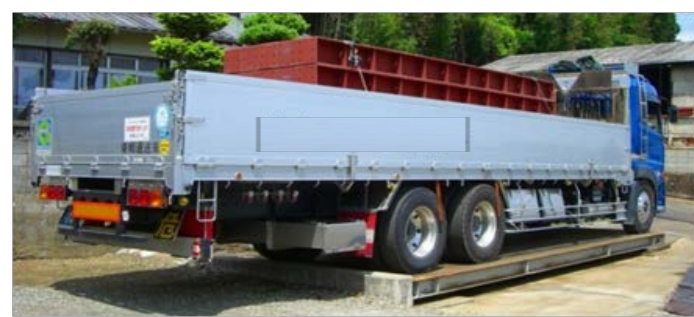

Fig. 5 Photo of experiment vehicle.

Table 1 Axle weight (in $\mathrm{kN}$ ) of the experiment vehicle.

\begin{tabular}{ccccc|cccc}
\hline & \multicolumn{4}{c|}{ First day } & \multicolumn{4}{c}{ Second day } \\
\cline { 2 - 8 } Axle & Front & Rear1 & Rear2 & Whole & Front & Rear1 & Rear2 & Whole \\
\hline Left & 35.8 & 47.8 & 41.7 & & 37.0 & 47.7 & 41.9 & \\
Right & 34.1 & 48.1 & 45.7 & & 36.2 & 49.7 & 45.9 & \\
Total & 69.9 & 95.9 & 87.4 & 253 & 73.2 & 97.4 & 87.8 & 258 \\
\hline
\end{tabular}

Table 2 Vehicle speed and number of runs.
Formatted: Font color: Auto

Formatted: Font color: Auto 


\begin{tabular}{|c|c|c|c|c|c|}
\hline \multirow{2}{*}{$\begin{array}{c}\text { Case } \\
\text { ID }\end{array}$} & \multirow{2}{*}{$\begin{array}{l}\text { Target speed } \\
(\mathrm{km} / \mathrm{h})\end{array}$} & \multirow{2}{*}{$\begin{array}{c}\text { Average } \\
\text { speed }(\mathrm{km} / \mathrm{h})\end{array}$} & \multicolumn{2}{|c|}{ Number of runs } & \multirow[t]{2}{*}{ Remark } \\
\hline & & & Intact & Damage & \\
\hline $\mathrm{V} 1$ & 10 & 11.43 & 4 & 3 & \\
\hline V2 & 20 & 18.64 & 7 & 6 & \\
\hline V3 & 40 & 36.71 & 7 & 6 & \\
\hline V4 & $10,20,40$ & & 18 & 15 & $\mathrm{~V} 1+\mathrm{V} 2+\mathrm{V} 3$ cases \\
\hline
\end{tabular}




\section{Damage-Detection Method}

\subsection{AR Model and Modal-Parameter Identification}

An autoregressive (AR) model is adopted to fit the time series of the measured bridge acceleration responses and then to identify the dominant frequencies and corresponding damping ratios of the bridge. Its algorithm is briefly described here while further details can be found in many other existing works e.g. [16, 30].

Given a set of discrete time series $y(k)$ of length $N(k=1, \ldots, N)$, it can be regarded as the output generated from an AR linear dynamic system of order $p$ as

$$
y(k)=\sum_{i=1}^{p} a_{i} y(k-i)+e(k)
$$

where $a_{i}$ is the $i$-th AR coefficient to be estimated and $e(k)$ the error term. Multiplying Eq. (1) by $y(k-s),(s=1, \ldots, p)$, and taking expected value (denoted as E[.]) yields the Yule-Walker equation, which is expressed as

$$
\mathbf{R a}=-\mathbf{r}
$$

where $\mathbf{R}$ is the Toeplitz autocorrelation matrix assembled with elements $R_{s, I}=r_{s-I}=\mathrm{E}[y(k-s) y(k-i)]$ defined as the autocorrelation function of $y(k) ; \mathbf{a}=\left[a_{1}, \ldots, a_{p}\right]^{\mathrm{T}} ; \mathbf{r}=\left[r_{1}, \ldots, r_{p}\right]^{\mathrm{T}}$. AR coefficients $a_{i}$ can be solved by any effective solution technique involving a Toeplitz matrix, e.g. the Levinson-Durbin algorithm [30].

Taking the z-transform of Eq. (1) yields

$$
Y(z)=H(z) E(z)=\frac{1}{1+\sum_{i=1}^{p} a_{i} z^{-i}} E(z)
$$

where $Y(z)$ and $E(z)$ are z-transforms of $y(k)$ and $e(k)$, respectively, $H(z)$ the transfer function of the system, and $z^{-i}$ the forward shift operator. The system's characteristic equation is then obtained by letting the denominator of $H(z)$ equal zero, i.e.

$$
z^{p}+a_{1} z^{p-1}+a_{2} z^{p-2}+\cdots+a_{p-1} z+a_{p}=0
$$

The complex conjugate roots, $z_{k}$ and $z^{*}{ }_{k}$ of Eq. (4) are the poles of the system, which have been proven to relate to the frequencies $\omega_{k}$ and damping ratios $h_{k}$ of the system as (taking the $k$-th mode for example)

$$
z_{k}, z_{k}^{*}=\exp \left(-h_{k} \omega_{k} \pm j \omega_{k} \sqrt{1-h_{k}^{2}}\right)
$$

where $j$ is the imaginary unit. 
Not all the system frequencies and damping ratios thus calculated are related to true bridge vibration modes. Some of them are related to other physical modes such as vehicle dynamics, road surface roughness, measurement noise and so on, while some of them relate to non-physical modes that present only for better fitting the mathematical model to the measured time series. To identify bridge vibration modes of our interest, certain subjective judgments are required. In this study, the judgment is made with the aid of (1) the singular value spectra yielded by performing frequency domain decomposition (FDD) [31] and (2) the stability diagrams obtained by performing multivariate AR analysis with respect to a wide range of orders [32].

\subsection{Nair's Damage Indicator}

Nair's damage indicator (NDI) is defined as [25]:

$$
\mathrm{NDI}=\frac{\left|a_{1}\right|}{\sqrt{a_{1}^{2}+a_{2}^{2}+a_{3}^{2}}}
$$

It is simply a function of the first three AR coefficients. Therefore, nothing related to modal information is required and thus neither is subjective judgment, indicating that automatic calculations are possible. The only parameter that has to be determined is the AR order. Several existing information criteria, e.g. the Akaike information criterion (AIC) [33] adopted herein, can be used to non-subjectively determine an optimal order from a number of candidate orders. This optimal order is that with which the numerical model is best fitted to the measured data series, while a certain large-order penalty is introduced. AIC is defined as AIC $=-2(\mathrm{ML})+2(\mathrm{NP})$, where ML denotes the maximum logarithm likelihood and NP the number of independently adjusted parameters within the model. The AR coefficients estimated with this optimal order, denoted as $M_{o}$, can thus be substituted into Eq. (6) to yield the NDI value.

It is worthy of noting that previously other damage indicators similar to the NDI expression were tested in consideration of different combinations of AR coefficients, e.g. [20, 26]

$$
\mathrm{DI}_{M}=\frac{\left|a_{1}\right|}{\sqrt{\sum_{i=1}^{M} a_{i}^{2}}}
$$

where $M$ is the number of AR coefficients. In the corresponding laboratory experimental sensitivity study on the parameter $M, \mathrm{DI}_{3}$ (exactly equivalent to NDI) was found to be the most sensitive indictor to damage. Hence, in this study, NDI is used without any additional sensitivity analysis on other similar forms of damage indicators. 


\subsection{Mahalanobis-Taguchi System for Decision Making}

For the intact bridge, the candidate damage indicators, either the modal parameters or NDI, identified from the dynamic responses of several runs (or observations) may form a certain statistical pattern, while those for the damaged bridge may not follow this pattern. Based on this knowledge, the bridge damage can be detected by first recognizing the pattern of the observations of the intact bridge and then testing if a new observation, from the intact or damaged bridge, follows the above pattern or not: if yes, it is classified as intact; if not, it is classified as damage. To achieve this task, the Mahalanobis-Taguchi system (MTS), a multivariate pattern-recognition tool, is adopted in this study. The algorithm is introduced as follows.

Given $n$ observations, $\boldsymbol{x}_{p}=\left[x_{p 1}, x_{p 2}, \ldots, x_{p k}\right], p=1 \sim n$, collected from the intact condition with respect to $k$ variables as

$$
\mathbf{x}=\left[\begin{array}{c}
\mathrm{x}_{1} \\
\mathrm{x}_{2} \\
\vdots \\
\mathrm{x}_{n}
\end{array}\right]=\underbrace{\left[\begin{array}{cccc}
x_{11} & x_{12} & \cdots & x_{1 k} \\
x_{21} & x_{22} & \cdots & x_{2 k} \\
\vdots & \vdots & \ddots & \vdots \\
x_{n 1} & x_{H 2} & \cdots & x_{k / k}
\end{array}\right]}_{k \text { variables }} \quad n \text { obscrvations }
$$

These observations form a 'reference' group, called Mahalanobis space (MS) or unit space, after being normalized by the mean $\mu_{i}$ and standard deviation $\sigma_{i}$ of the $i$-th variable, i.e. $X_{p i}=\left(x_{p i}-\mu_{i}\right) / \sigma_{i}, i=$ $1 \sim k, p=1 \sim n$. With the MS, the Mahalanobis distance (MD) can be calculated for the $p$-th observation using the following equation

$$
\mathrm{MD}_{p}=\frac{1}{k} \mathbf{X}_{p} \cdot \mathbf{R}_{\mathrm{MD}}^{-1} \cdot \mathbf{X}_{p}^{T}
$$

where $\boldsymbol{X}_{p}=\left[X_{p 1}, X_{p 2}, \ldots, X_{p k}\right]$ and $\mathbf{R}_{\mathrm{MD}} \in \mathrm{R}^{n \times k}$ denotes the correlation matrix assembled with the elements $r_{i j}=\sum_{m=1}^{n} X_{m i} /\left(\sum_{m=1}^{n} X_{m i}^{2} \cdot \sum_{m=1}^{n} X_{m j}^{2}\right)^{1 / 2}$. As can be seen from Eq. (8), and as shown in Fig. 6 also, MD is a single measure of the distance in multidimensional space taking correlations into account. In MTS, it is taken to measure the degree of abnormality of any candidate observation and therefore to detect the health condition of the bridge from which the candidate observation is measured. For a candidate observation $\boldsymbol{y}_{q}=\left[y_{q 1}, y_{q 2}, \ldots, y_{q k}\right]$, measured from the intact or damaged bridge, with respect to the same $k$ variables, its MDs are calculated with the same correlation matrix $\mathbf{R}_{\mathrm{MD}}$ of the MS as follows,

$$
\overline{\mathrm{MD}}_{q}=\frac{1}{k} \mathbf{Y}_{q} \cdot \mathbf{R}_{\mathrm{MD}}^{-1} \cdot \mathbf{Y}_{q}^{T}
$$


where $\boldsymbol{Y}_{q}=\left[Y_{q 1}, Y_{q 2}, \ldots, Y_{q k}\right]$ with elements $Y_{q i}=\left(y_{q i}-\mu_{i}\right) / \sigma_{i}, i=1 \sim k$, is the observation vector normalized with the mean and standard deviation of the MS.

Theoretically, the MDs corresponding to intact conditions are small while those from damage conditions are large. To make a quantitative decision on the health condition, a threshold is necessary. Herein, the threshold is determined in an objective way: by cross validation [29]. First we treat the 1st observation from $n$ observations of the intact (reference) condition as the candidate observation and take the normalized vectors of the remaining $n-1$ observations as the MS to calculate the MD of the 1st observation. Repeating this step $n$ times by treating each observation as a candidate observation one by one yields $n$ MDs. Removing the largest and smallest MD values to reduce the effect of possible outliers, the mean of the remaining $n-2$ MDs, termed the trimmed mean, is taken as the threshold for future damage detection.

It should be noted that the MTS adopted herein is not a full version, which would also include the identification of useful variables, following the above algorithm, with the aid of orthogonal arrays $(\mathrm{OA})$ and signal-to-noise $(\mathrm{S} / \mathrm{N})$ ratios $[27,28]$.The identification of useful variables is excluded because every variable (assigned in next section) is regarded as important so cannot be removed and therefore all the variables collected from a candidate sensor set (assigned in next section) are used to detect bridge damage.

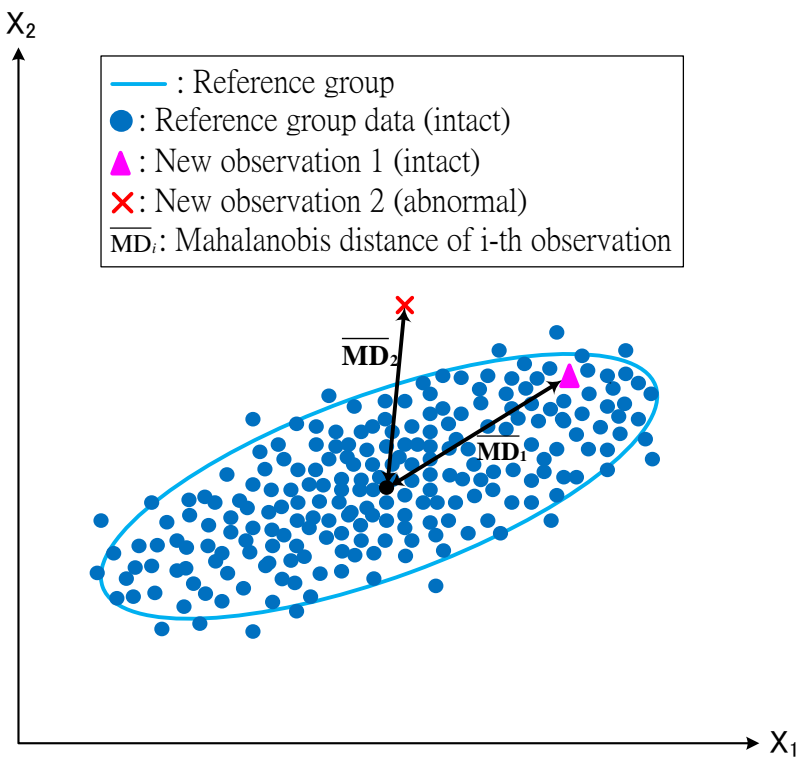

Fig. 6 Illustration of Mahalanobis distance (MD). 

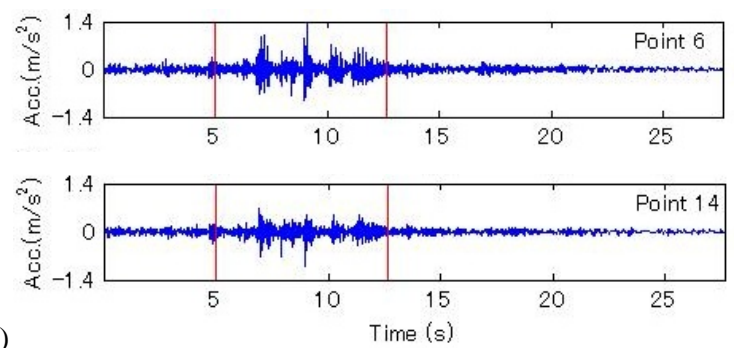

(a)
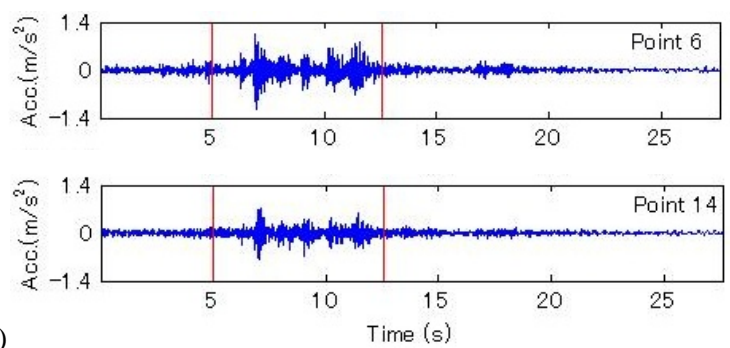

Fig. 7 Vehicle-induced bridge accelerations: (a) intact ( $v=40 \mathrm{~km} / \mathrm{h}$, Run1); (b) damage ( $v=40 \mathrm{~km} / \mathrm{h}$,

Run3). Note: vertical lines at $5 \mathrm{~s}$ and $12.5 \mathrm{~s}$ mark the entrance and exit of the experiment vehicle respectively.

\subsection{Results and Discussions}

\subsubsection{Modal Parameter MTS Analysis Results}

\subsection{Modal Parameter Identification Example}

It is useful to illustrate this damage-detection method with an example. Fig. 7 shows example runs of bridge acceleration responses at measurement points No. 6 and No. 14 when the truck passed with a speed of $40 \mathrm{~km} / \mathrm{h}$ (Case V3) for both intact and damage conditions. From this figure, it is not easy to identify any specific change in acceleration responses caused by the artificial damage.

To identify meaningful modal parameters, FDD is performed on the response set from all measurement points for one run in order to obtain a singular spectrum, where dominant modes may show a peak at their corresponding modal frequency. Also, multivariate AR analysis is performed on the response sets - with respect to a wide range of model order - in order to obtain a stability diagram, where meaningful modes may present a vertical line corresponding to their corresponding modal frequency. Fig. 8 shows the stability diagrams superimposed by the singular spectra of vehicle-induced bridge accelerations of the same run as in Fig. 7. The identification of meaningful 
bridge modes is carried out manually and subjectively by picking the modes that satisfy the following criteria: (a) presenting a peak at corresponding frequency in the singular spectrum; (b) presenting a vertical line at corresponding frequency in the stability diagram; (c) appearing in repeated runs (more results not shown here); (d) has a mode shape consistent with a physical interpretation. According to these criteria, two meaningful bridge modes are identified as shown in Fig. 9, one (designated as the 1st mode hereafter) with modal frequency around $1.96 \mathrm{~Hz}$ and the other (designated as the 2nd mode hereafter) around $7.64 \mathrm{~Hz}$. Comparing those two modes for intact and damage conditions, little change occurs in modal frequencies while obvious change in damping ratios and mode shapes (especially at the nodes near the artificial damage) are observed as damage is applied.
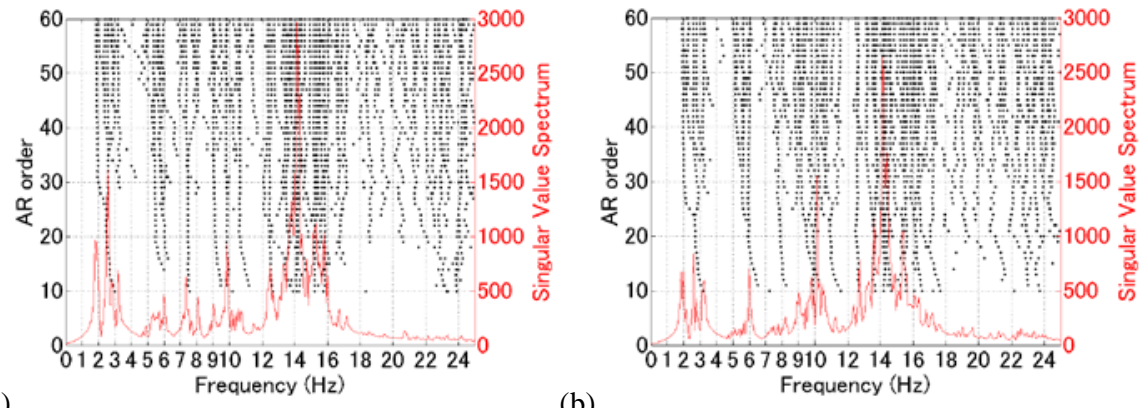

(a)

Fig. 8 Stability diagram and singular spectrum of vehicle-induced bridge accelerations: (a) intact ( $v=40 \mathrm{~km} / \mathrm{h}$, Run1); (b) damage ( $v=40 \mathrm{~km} / \mathrm{h}$, Run 3).

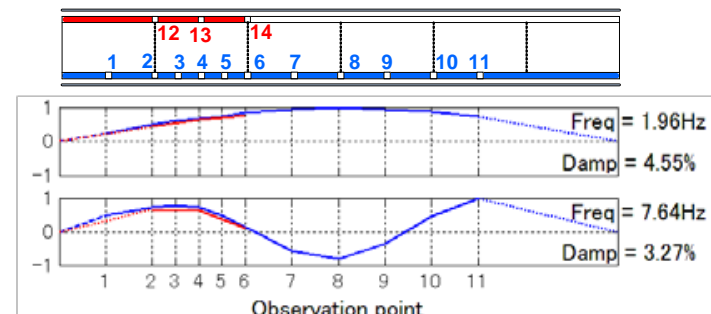

(a)

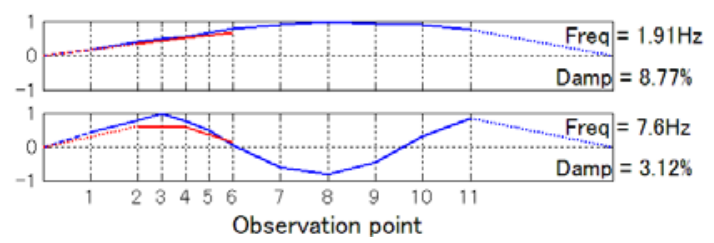

(b)

Observation point

Formatted: Font color: Auto 
Fig. 9 Identified mode shapes along with modal frequencies and damping ratios: (a) intact; (b) damage.

Several issues should be noted herein. Firstly, if the response set from all 12 nodal measurement points is analysed, i.e. all measurement points excluding No. 3 and 5, rather than those from all 14 measurement points, the identified results (not shown here) remain similar. This is likely to be a result of the global modal properties not being significantly affected by local vibration responses. Secondly, the modal parameter-identification approach is not limited to the present one as it is not the major focus of this study, however, the statistical properties of the identified modal parameters are. Any effective alternative approach can be adopted to identify modal parameters of the bridge. Thirdly, higher modes may provide more damage information and prove to be more damage-sensitive than the above two identified modes, but they are hard to identify precisely and stably and therefore are not given further consideration here. Lastly, it is recognized that the vehicle-bridge system is time-variant and the frequency of this system may vary as a function of vehicle location. However, the frequency variation can be negligible and the system regarded as time-invariant if the vehicle mass is small enough (say, less than $10 \%$ of the bridge mass) and the vehicle frequency is not close to the bridge frequency [34]; this is exactly the criteria that met in this study. Therefore it can be claimed that the modal-parameter identification methods, AR and FDD methods, employed herein are valid.

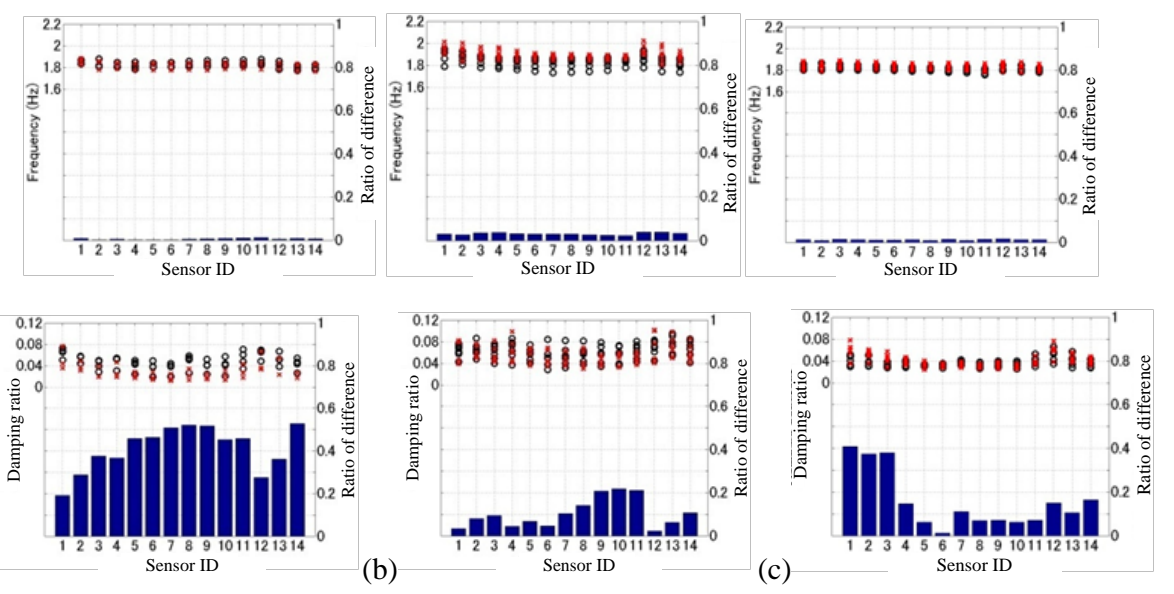

Fig. 10 Identified 1st modal frequencies (top) and damping ratios (bottom) for the intact (o) and damaged bridge (x) and their ratios of difference (bar w.r.t. right vertical axis): (a) Case V1; (b) Case V2; (c) Case V3. 


\subsection{Basic Statistical Properties}

After the two meaningful bridge modes are identified, it is possible to focus only on those two modes in single-variate AR analysis afterwards, i.e., perform the single-variate AR analysis on a single response from one measurement point and then pick the modes with dominant frequency near $1.96 \mathrm{~Hz}$ or $7.64 \mathrm{~Hz}$. By performing this analysis on the responses obtained from every measurement point in every run and every case, the modal frequencies and damping ratios of every run can be identified. Fig. 10 shows the identified 1 st modal frequencies $f_{1}$ and damping ratios $d_{1}$ with respect to all 14 measurement points and Cases V1 to V3, for both the intact and damage conditions. The ratios of the difference (in mean) between intact and damage conditions are also shown in Fig. 10, relative to the intact condition. Several basic statistical observations can be made as follows;

(1) $f_{1}$ was not very sensitive to damage, presenting little difference between intact and damage conditions and generally smaller than a ratio of 5\%;

(2) $d_{1}$ was more sensitive than $f_{1}$ to damage because it presents larger difference, generally larger than a ratio of $10 \%$;

(3) the relationship between the damage location and the rate of change in $f_{1}$ or $d_{1}$ was not clear;

(4) the effect of vehicle speed on the identified modal parameters was not clear, e.g. Case V2 ( $v$ $=20 \mathrm{~km} / \mathrm{h}$ ) gives larger rates of frequency change than the other two cases, but Case V1 ( $v$ $=10 \mathrm{~km} / \mathrm{h}$ ) gives larger rates of damping-ratio change than the other two cases.

The identified 2nd modal frequencies $\left(f_{2}\right)$ and damping ratios $\left(d_{2}\right)$ also present similar statistical observations (results not shown here) with low sensitivity of $f_{2}$, higher sensitivity of $d_{2}$ to damage, no clear relationship between damage location and rate of change in frequency or damping ratio, and no clear effect of vehicle speed.

It should be noted that obtaining an accurate measure of damping is very challenging. For example, a damping ratio of $8.77 \%$ is observed in Fig. 9(b), which is higher than commonly observed ones. To validate it, an independent Stochastic Space Identification (SSI) [35] was performed on the same time response data set. The identified frequency and damping ratio were 1.94 $\mathrm{Hz}$ and $8.15 \%$ respectively, which were close to the corresponding values identified by the AR method. These outcomes validate each other but evaluation of which one is more effective is outside the scope of this paper. Moreover, acknowledging this aforementioned fact does not straightforwardly lead to damping (and its statistical properties) not being feasible for the purpose of damage detection. At a minimum, it should be tested for the experimental data. In particular, as the 
data was collected from a rare field damage experiment, it is valuable to test damping in this scenario. Therefore, damping ratios are retained as candidate variables for damage detection.

\subsection{Damage Detection}

As mentioned earlier for the intact condition, the identified modal frequencies or damping ratios from different measurement points for many runs may form a specific pattern. However, the modal parameters for the damage condition may not follow this pattern. This forms the motivation for the application of the pattern-recognition tool, MTS. Before applying MTS, the variables of MTS should be properly chosen. In this section, the variables are chosen to be the modal frequencies or damping ratios identified from a set of measurement points (or sensors). The sensor set could be a factor affecting the pattern information and subsequent health-condition classification, which is also investigated as follows. Table 3 lists the investigated sensor sets, where Set 1 consists of all 14 sensors; Set 2: all sensors at nodes; Set 3: all sensors on the damaged side; Set 4: all sensors at nodes on the damaged side; Set 5: the midspan-symmetric sensors at truss nodes on the damaged side; Set 6: the midspan-symmetric sensors at every second node on the damaged side; Sets 7A to 7J: sensors at adjacent nodes; and finally, Sets $7 \mathrm{~B}_{\mathrm{L}}, 7 \mathrm{~B}_{\mathrm{R}}, 7 \mathrm{C}_{\mathrm{L}}$ and $7 \mathrm{C}_{\mathrm{R}}$ :two adjacent sensors with one at a node and the other not at a node.

Although there are a large number of sensor sets, each set has its own importance. Basically, Sets 1 to 6 are used for damage detection and each set is a representative of one specific sensor allocation pattern, as indicated in Table 3. Sets 7A to 7J utilize pairs of sensors i.e. two sensors each. These sets are used for damage localization, which usually requires more local information; therefore there are a number of these types of set to incorporate a range of sensor pairings. It follows that there is some overlap between sets in terms of sensors used; some sensors are used in more than one set. 
Table 3 Sensor sets.

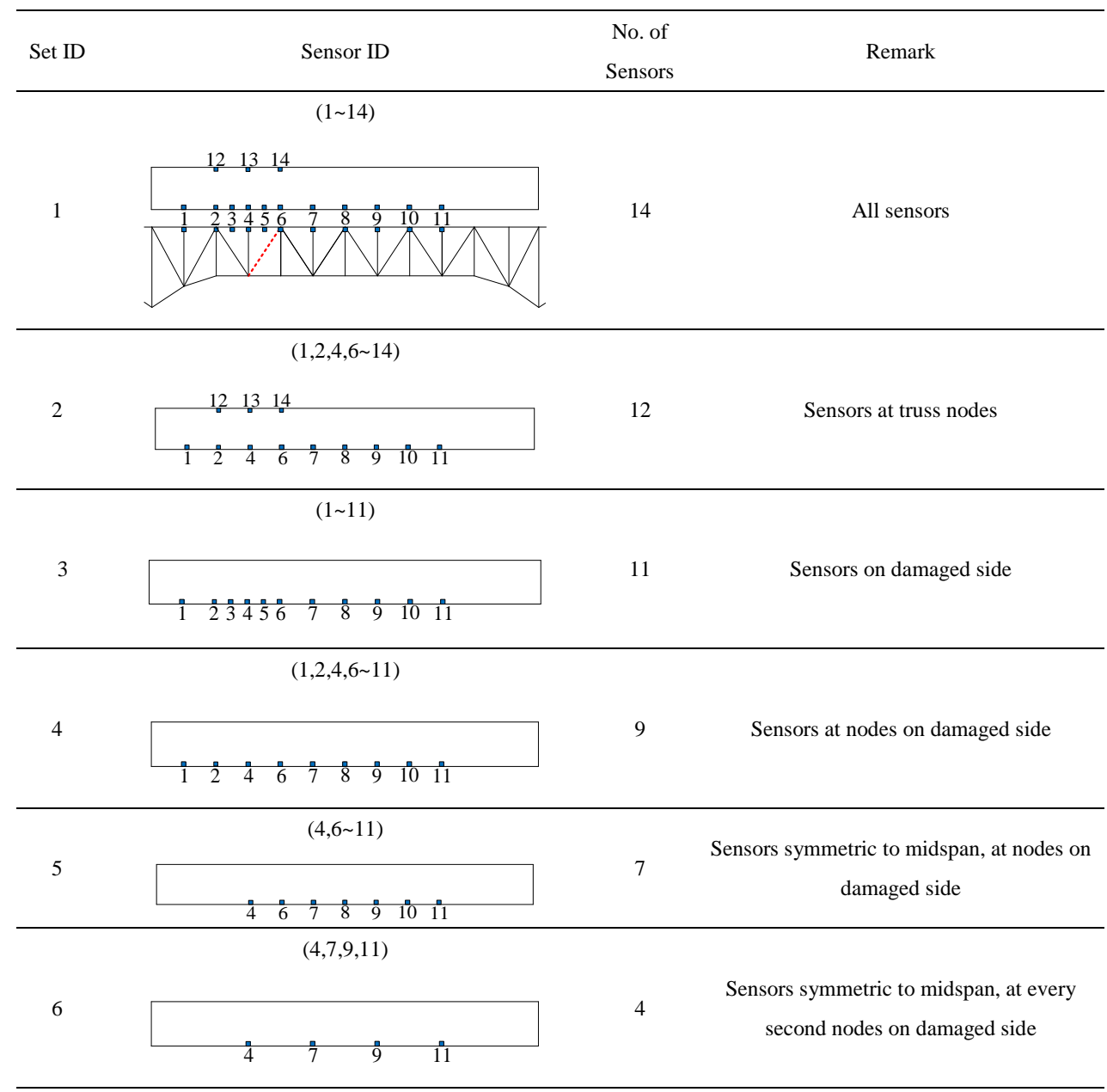

\section{$\mathrm{A}(1,2) ; \mathrm{B}_{\mathrm{L}}(2,3) ; \mathrm{B}_{\mathrm{R}}(3,4) ; \mathrm{C}_{\mathrm{L}}(4,5) ; \mathrm{C}_{\mathrm{R}}(5,6) ; \mathrm{D}(6,7) ; \mathrm{E}(7$}

7A, $\quad$,8); $\mathrm{F}(8,9) ; \mathrm{G}(9,10) ; \mathrm{H}(10,11) ; \mathrm{I}(12,13) ; \mathrm{J}(13,14)$

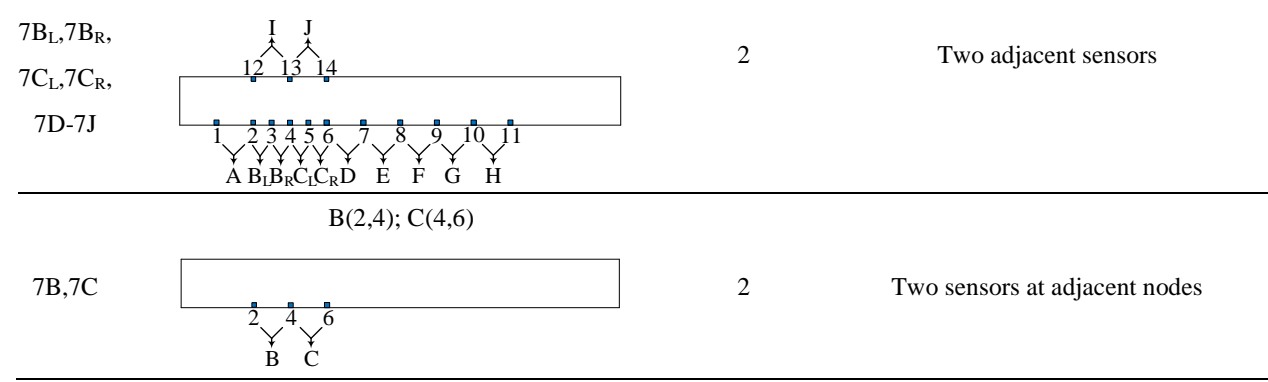



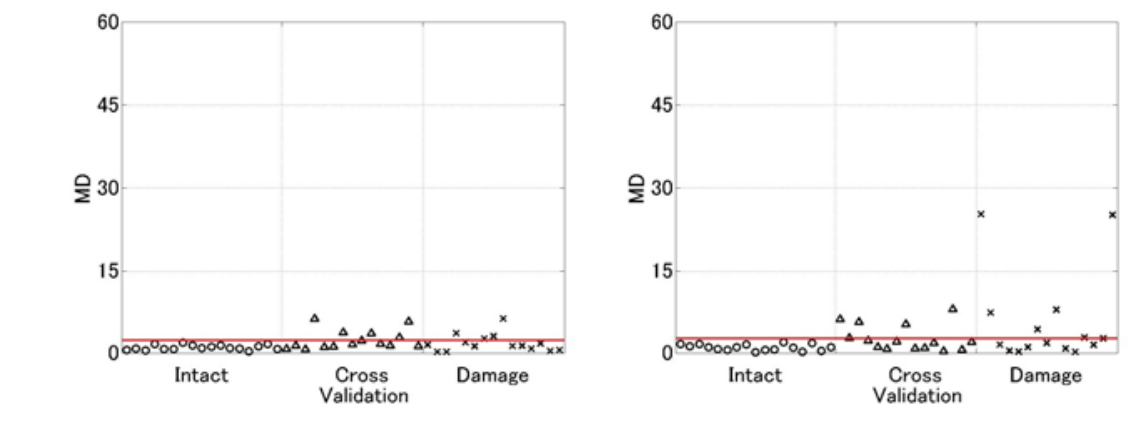

(a)
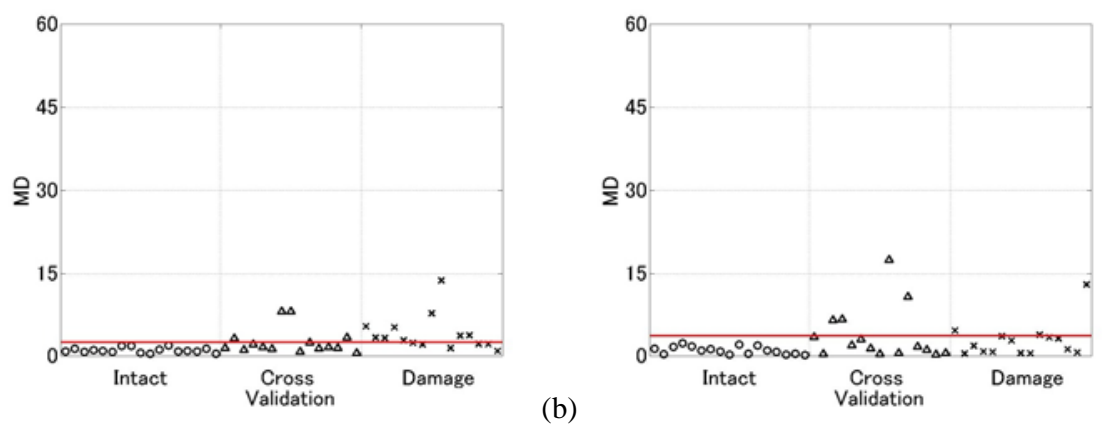

Fig. 11 MD calculated with (a) the 1st and (b) 2nd modal frequencies (top) and damping ratios (bottom) of the sensor Set 5 as variables. (Case V4)

Take the sensor Set 5 for example. Taking the $f_{1}$ identified for the sensors in Set 5 as variables and taking all 18 observations (runs) of Case V4 for the intact condition to construct the MS, one can calculate the MD of each observation for the intact condition as well as for the damage condition (15 observations), as shown at the top of Fig. 11(a). Also, the MDs used for cross validation and the threshold calculated from them are plotted in the same figure. The same procedure can also be done if the candidate damage indicator is changed from $f_{1}$ to $d_{1}, f_{2}$ or $d_{2}$, yielding the MD results shown in the other parts of Fig. 11. It is visually observed that, as damage is applied, the MD generally increases regardless of whether the damage indicator is $f_{1}, d_{1}, f_{2}$ or $d_{2}$. However, so too does the MD for the cross validation, with some magnitudes larger than those of the damage condition and some smaller, making the damage-detection task difficult to achieve by simple visual readings. Hence it is proposed to make the decision on health condition with the aid of two MD-derived quantities: the ratio and mean of the MD over the threshold. The criteria for successful damage detection requires both the ratio and mean of the MD over the threshold to be larger for the damage condition than for cross validation - it fails if neither is larger. Finally, the damage detection is unconfirmed if either

Formatted: Font color: Auto

Formatted: Font color: Auto 
one is larger. Following these criteria, the damage detection failed for $f_{1}$, with both the ratio (27\%) and mean (1.0) of the MD of the damage condition smaller than those (33\% and 1.5) of cross validation; it was successful for $f_{2}$, with both the ratio (47\%) and mean (5.0) of the MD of the damage condition larger than those (33\% and 1.9) of cross validation. For $d_{1}$ and $d_{2}$, the damage detection was successful for the former but failed for the latter.

This damage detection procedure can be performed on all the other sensor sets. Taking $f_{1}, f_{2}, d_{1}$ and $d_{2}$ respectively of sensor Sets 1 to 6 as variables of MTS, the ratios and means of MD over the threshold are obtained, with which the damage-detection task can be evaluated as successful, failed or unconfirmed, as summarized in Table 4. It is observed that only about half of the cases were successful in damage detection, indicating that the statistical patterns of modal parameters are not sensitive enough to damage. Damage detection was successful for certain modal parameters of certain sets of measurement point, e.g. $d_{1}$ of Set $2, f_{1}$ and $d_{1}$ of Set $3, d_{1}$ of Set 4 , etc., but no specific rule could be followed in order to choose effective modal parameters and suitable sets.

Table 4 Ratios and means of MD over the threshold (variables: the 1st and 2nd modal

\begin{tabular}{|c|c|c|c|c|c|}
\hline Set ID & Variables & Condition & Ratio (\%) & Mean & Damage Detection* \\
\hline \multirow[t]{12}{*}{1} & \multirow{3}{*}{$f_{1}$} & Intact & 0 & 0 & \multirow{3}{*}{$x$} \\
\hline & & Cross & 94 & 773 & \\
\hline & & Damage & 87 & 159 & \\
\hline & \multirow{3}{*}{$f_{2}$} & Intact & 0 & 0 & \multirow{3}{*}{$x$} \\
\hline & & Cross & 88 & 4160 & \\
\hline & & Damage & 73 & 517 & \\
\hline & \multirow{3}{*}{$d_{1}$} & Intact & 0 & 0 & \multirow{3}{*}{$\Delta$} \\
\hline & & Cross & 88 & 566 & \\
\hline & & Damage & 100 & 285 & \\
\hline & \multirow{3}{*}{$d_{2}$} & Intact & 0 & 0 & \multirow{3}{*}{$\times$} \\
\hline & & Cross & 82 & 19600 & \\
\hline & & Damage & 73 & 134 & \\
\hline \multirow[t]{12}{*}{2} & \multirow{3}{*}{$f_{1}$} & Intact & 0 & 0 & \multirow{3}{*}{$x$} \\
\hline & & Cross & 76 & 98 & \\
\hline & & Damage & 73 & 92 & \\
\hline & \multirow{3}{*}{$f_{2}$} & Intact & 0 & 0 & \multirow{3}{*}{$\times$} \\
\hline & & Cross & 71 & 1450 & \\
\hline & & Damage & 47 & 108 & \\
\hline & \multirow{3}{*}{$d_{1}$} & Intact & 0 & 0 & \multirow{3}{*}{$\mathrm{O}$} \\
\hline & & Cross & 76 & 94 & \\
\hline & & Damage & 87 & 169 & \\
\hline & \multirow{3}{*}{$d_{2}$} & Intact & 0 & 0 & \multirow{3}{*}{$\times$} \\
\hline & & Cross & 65 & 538 & \\
\hline & & Damage & 60 & 68 & \\
\hline
\end{tabular}

*Note: O: successful; $\Delta$ : unconfirmed; $\times$ : failed. 
Table 4 (continued)

\begin{tabular}{|c|c|c|c|c|c|}
\hline Set ID & Variables & Condition & Ratio (\%) & Mean & Damage Detection* \\
\hline \multirow[t]{12}{*}{3} & \multirow{3}{*}{$f_{1}$} & Intact & 0 & 0 & \multirow[t]{3}{*}{ 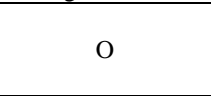 } \\
\hline & & Cross & 59 & 74 & \\
\hline & & Damage & 67 & 88 & \\
\hline & \multirow{3}{*}{$f_{2}$} & Intact & 0 & 0 & \multirow{3}{*}{$\Delta$} \\
\hline & & Cross & 59 & 522 & \\
\hline & & Damage & 60 & 405 & \\
\hline & \multirow{3}{*}{$d_{1}$} & Intact & 0 & 0 & \multirow{3}{*}{$\mathrm{O}$} \\
\hline & & Cross & 65 & 88 & \\
\hline & & Damage & 93 & 130 & \\
\hline & \multirow{3}{*}{$d_{2}$} & Intact & 0 & 0 & \multirow{3}{*}{$x$} \\
\hline & & Cross & 59 & 570 & \\
\hline & & Damage & 47 & 62 & \\
\hline \multirow[t]{12}{*}{4} & \multirow{3}{*}{$f_{1}$} & Intact & 0 & 0 & \multirow{3}{*}{$\times$} \\
\hline & & Cross & 35 & 43 & \\
\hline & & Damage & 33 & 22 & \\
\hline & \multirow{3}{*}{$f_{2}$} & Intact & 0 & 0 & \multirow{3}{*}{$\times$} \\
\hline & & Cross & 47 & 177 & \\
\hline & & Damage & 33 & 70 & \\
\hline & \multirow{3}{*}{$d_{1}$} & Intact & 0 & 0 & \multirow{3}{*}{$\mathrm{O}$} \\
\hline & & Cross & 41 & 57 & \\
\hline & & Damage & 87 & 109 & \\
\hline & \multirow{3}{*}{$d_{2}$} & Intact & 0 & 0 & \multirow{3}{*}{$\times$} \\
\hline & & Cross & 47 & 358 & \\
\hline & & Damage & 27 & 25 & \\
\hline \multirow[t]{12}{*}{5} & \multirow{3}{*}{$f_{1}$} & Intact & 0 & 0 & \multirow{3}{*}{$\times$} \\
\hline & & Cross & 33 & 1.5 & \\
\hline & & Damage & 27 & 1.0 & \\
\hline & \multirow{3}{*}{$f_{2}$} & Intact & 0 & 0 & \\
\hline & & Cross & 33 & 1.9 & $\mathrm{O}$ \\
\hline & & Damage & 47 & 5.0 & \\
\hline & & Intact & 0 & 0 & \\
\hline & $d_{1}$ & Cross & 27 & 1.5 & $\mathrm{O}$ \\
\hline & & Damage & 60 & 3.3 & \\
\hline & & Intact & 0 & 0 & \\
\hline & $d_{2}$ & Cross & 27 & 2.7 & $x$ \\
\hline & & Damage & 20 & 1.4 & \\
\hline 6 & & Intact & 18 & 0.4 & \\
\hline & $f_{1}$ & Cross & 27 & 1.2 & $\mathrm{O}$ \\
\hline & & Damage & 40 & 2.2 & \\
\hline & & Intact & 12 & 0.4 & \\
\hline & $f_{2}$ & Cross & 33 & 1.5 & $\mathrm{O}$ \\
\hline & & Damage & 60 & 2.6 & \\
\hline & & Intact & 6 & 0.1 & \\
\hline & $d_{1}$ & Cross & 27 & 0.9 & $\mathrm{O}$ \\
\hline & & Damage & 67 & 3.6 & \\
\hline & & Intact & 6 & 0.2 & \\
\hline & $d_{2}$ & Cross & 40 & 1.3 & $\mathrm{O}$ \\
\hline & & Damage & 73 & 8.3 & \\
\hline
\end{tabular}



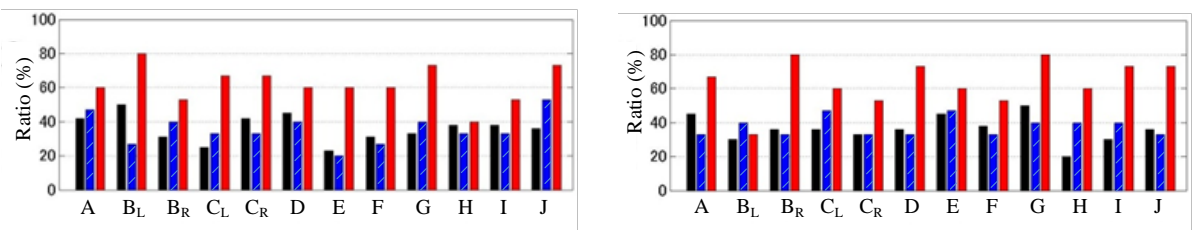

(a)

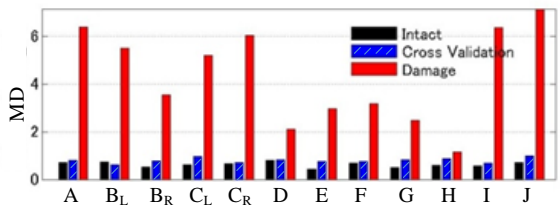

(b)

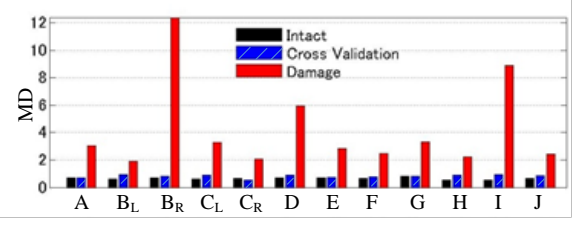

Fig. 12 Ratios (top) and means (bottom) of MD over threshold, calculated with the 1st (a) modal frequency and (b) damping ratio of Sets 7A, 7B $, 7 B_{R}, 7 C_{L}, 7 C_{R}$, and 7D-7J as variables. (Case V4)
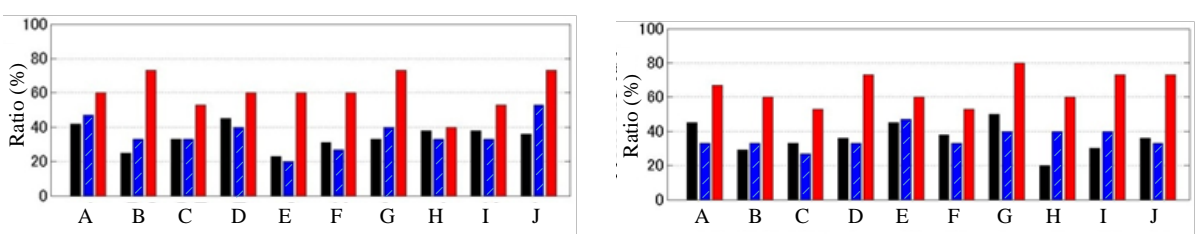

(a)
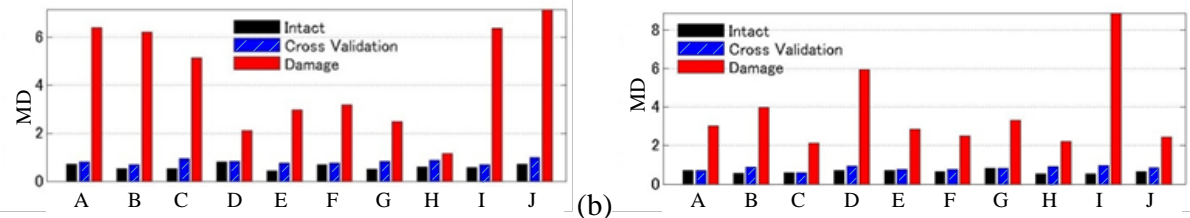

Fig. 13 Ratios (top) and means (bottom) of MD over threshold calculated with the 1st (a) modal frequency and (b) damping ratio of Sets 7A to 7J as variables. (Case V4)

\subsection{Damage Localization}

Further to damage detection, damage localization utilizing MTS on modal parameters is also investigated. To localize the damage, the smallest number of sensors are assigned to a set of MTS variables, say, two-sensor sets including Sets $7 \mathrm{~A}$ to $7 \mathrm{~J}, 7 \mathrm{~B}_{\mathrm{L}}, 7 \mathrm{~B}_{\mathrm{R}}, 7 \mathrm{C}_{\mathrm{L}}$ and $7 \mathrm{C}_{\mathrm{R}}$ as listed in Table 3. Fig. 12 shows the ratios and means of the MD over the threshold calculated with $f_{1}$ and $d_{1}$ of Sets 7A, $7 \mathrm{~B}_{\mathrm{L}}, 7 \mathrm{~B}_{\mathrm{R}}, 7 \mathrm{C}_{\mathrm{L}}, 7 \mathrm{C}_{\mathrm{R}}$, and 7D to $7 \mathrm{~J}$ (adjacent-sensor sets) as variables, while Fig. 13 shows those of Sets 7A to 7J (adjacent-nodal-sensor sets) as variables, both with all sums of Case V4 as observations. Although damage detection is guaranteed by showing larger ratios and means in MD over the threshold for the damage condition than for the cross validation, damage localization seems 
to be difficult here, without any significant deviation in MDs with respect to sensors near the artificial damage, whether the adjacent-sensor or adjacent-nodal-sensor sets are utilized. Replacing $f_{1}$ and $d_{1}$ with $f_{2}$ and $d_{2}$ also yields similar results (not shown here), indicating that damage localization is difficult to achieve whether the adjacent sensor or adjacent nodal sensor sets are taken as variables.

\subsection{Effect of Speed}

The effect of vehicle speed on the damage localization results is also investigated. As mentioned in Table 2, three vehicle speeds are considered: 10 (Case V1), 20 (Case V2) and $40 \mathrm{~km} / \mathrm{h}$ (Case V3). Fig. 14 shows the ratios and means of MD over threshold calculated with $f_{1}$ and $d_{1}$ of Sets 7A, 7B $7 B_{R}, 7 C_{L}, 7 C_{R}$, and 7D to 7J (adjacent-sensor sets) as variables for those speed cases. No clear effect of vehicle speed on the damage localization results is observed, indicated by the lack of any larger means and ratios of the MD over the threshold appearing in the sets near the damage. The lack of a clear effect is most likely due to too small a number of observations in each case (e.g. as few as 3 for Case V1 in the damage condition) to form a distinguishable statistical pattern. Based on this observation, the speed factor is not considered any further and all three speed cases are collected together as another case, Case V4, for the purpose of studying other factors.

In summary, although bridge damage detection can be achieved by performing MTS on certain modal parameters of certain sets of measurement points, several difficulties are faced: the first one is the subjective selection of meaningful bridge modes; the second one is the low sensitivity of the statistical pattern of modal parameters to damage.
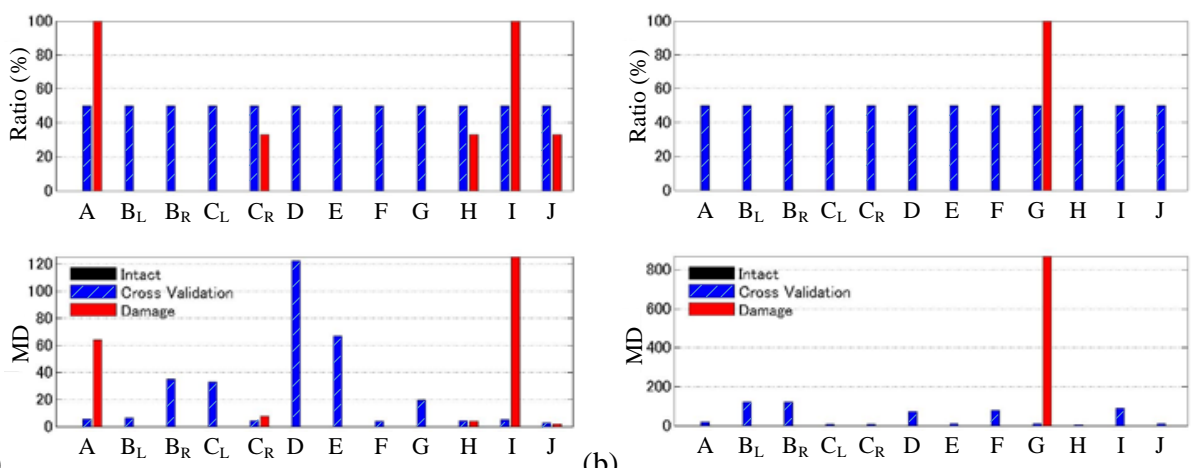

(a)

Fig. 14 Ratios (top) and means (bottom) of MD over threshold, calculated with the 1st moda frequency (left, i.e. (a), (c), (e)) and damping ratio (right, i.e. (b), (d), (f)) of Sets 7A, 7B $, 7 B_{R}, 7 C_{L}$, 7C , and 7D-7J in Case V1 ((a) and (b)), V2 ((c) and (d)) and V3 ((e) and (f)) as variables. 

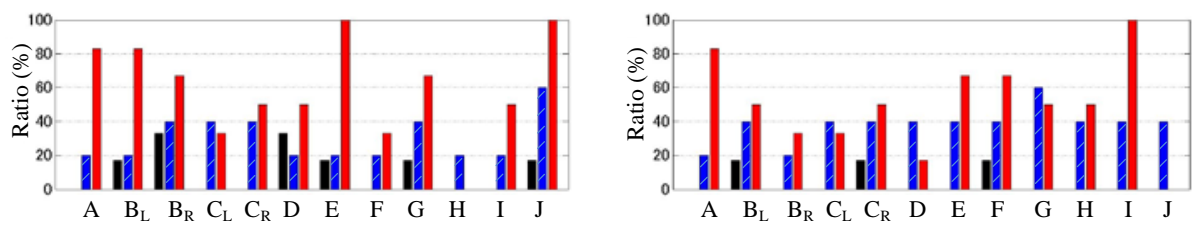

(c)

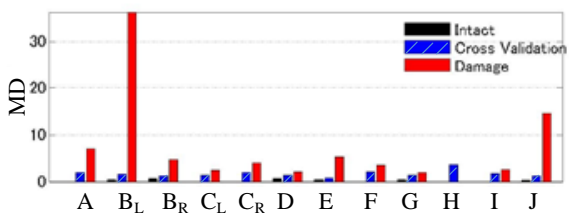

(d)
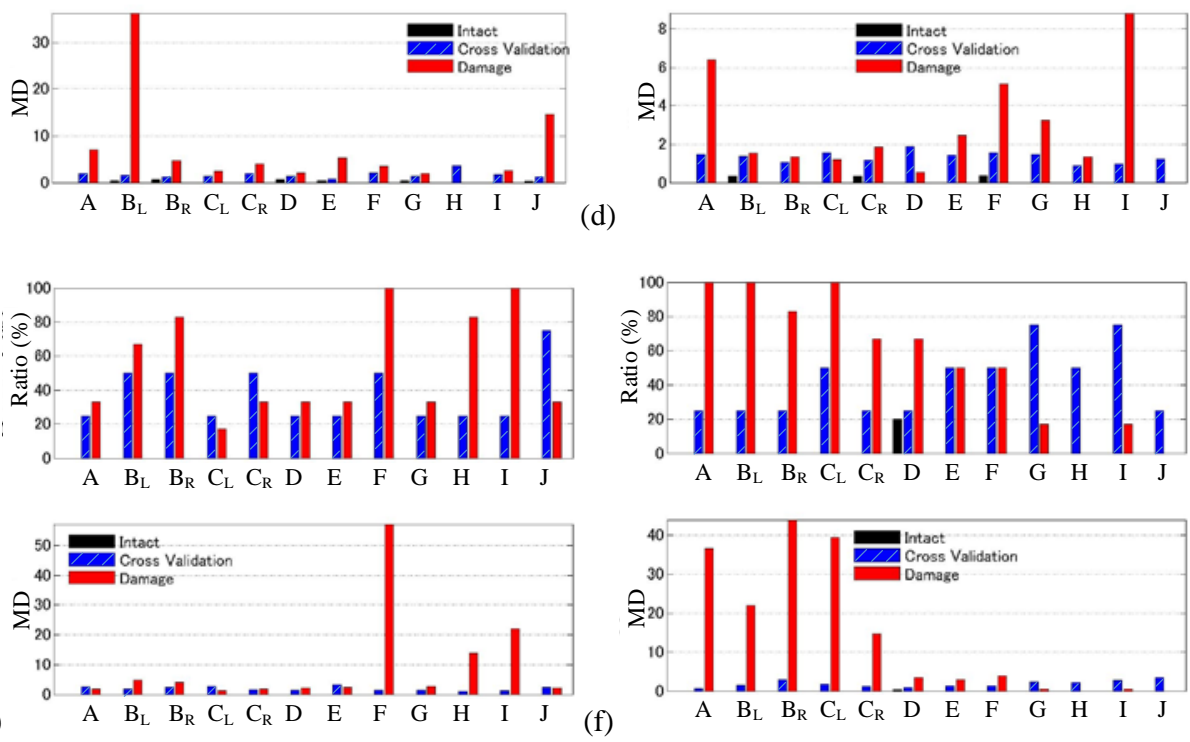

Fig. 14 (continued)

\subsubsection{NDI MTS Analysis Results}

\subsection{Damage Detection}

In this section, another damage indicator is examined: NDI as defined in Section 3.2. Fig. 15 shows the NDIs with respect to the 14 measurement points and Cases V1 to V3 for the intact and damage conditions, respectively, and their ratio of mean difference. It is observed through basic statistics that the means of NDI change as damage is applied, with ratios generally larger than those of $f_{1}$ but smaller than those of $d_{1}$. NDI's statistical pattern also changes obviously via visual inspection, which can be evaluated quantitatively by performing MTS as follows. Fig. 16 shows two example MTS results, one is the MD calculated with NDIs of sensor Set 5 and the other is that of sensor Set 6; the increase of MD due to the artificial damage can be easily observed from either. For sensor Set 5, damage detection is successful, with both larger ratio (100\%) and mean (13) of the MD over the threshold occurring for the damage condition compared to those (38\% and 2 ) for cross 
validation (see also Table 5). For sensor Set 6, damage detection is also successful, satisfying the same criteria. For other sets, the success or failure in damage detection tasks, according to the ratios and means of MD over threshold calculated for intact and damage conditions and cross validations are listed in Table 5. It is observed that most of the sensor sets offer successful damage detection, indicating that the NDI patterns are sensitive to damage regardless of the sensor sets considered herein. In concerning instrumentation and manpower costs, the sensor set with minimum number, i.e. Set 6 with 4 sensors at the damaged side in this study, could be an efficient layout that provides acceptably accurate prediction in practice.

(a)

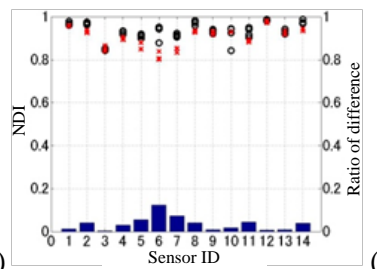

(b)
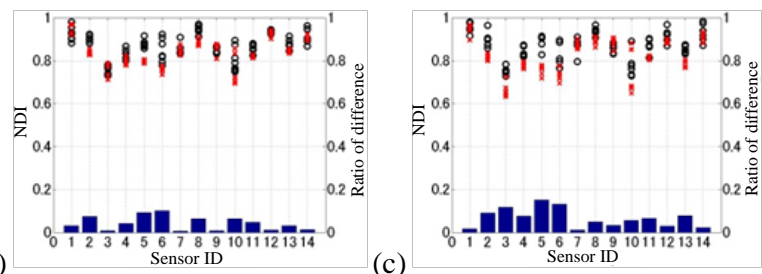

Fig. 15 NDI calculated from the intact (o) and damaged bridge (x) and their ratios of mean difference (bar w.r.t. right vertical axis): (a) Case V1; (b) Case V2; (c) Case V3.

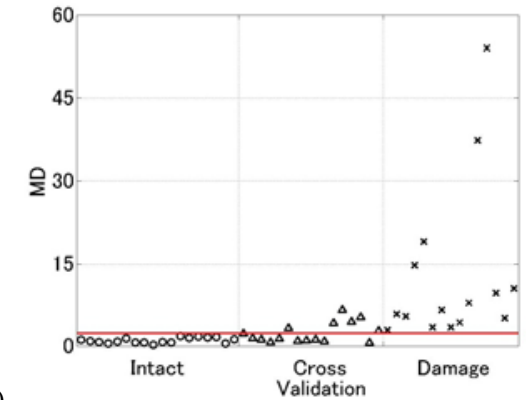

(a)

Fig. 16 MD calculated with NDI of (a) Set 5 and (b) Set 6 as variables.

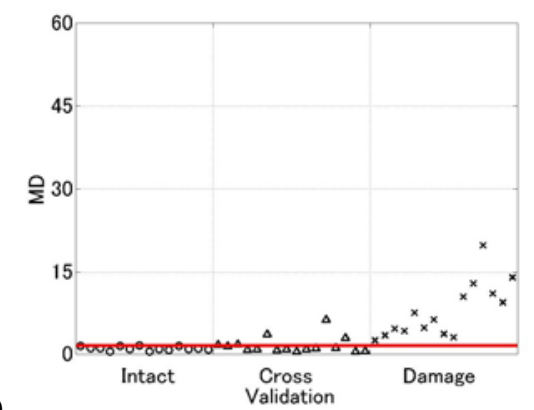

(b) 
Table 5 Ratios and means of MD over the threshold (variables: NDI of Sets 1 to 6).

\begin{tabular}{|c|c|c|c|c|}
\hline Set ID & Condition & Ratio (\%) & Mean & Damage Detection* \\
\hline \multirow{3}{*}{1} & Intact & 0 & 0 & \multirow{3}{*}{$\Delta$} \\
\hline & Cross & 78 & 65 & \\
\hline & Damage & 100 & 24 & \\
\hline \multirow{3}{*}{2} & Intact & 0 & 0 & \multirow{3}{*}{$\mathrm{O}$} \\
\hline & Cross & 61 & 9 & \\
\hline & Damage & 93 & 10 & \\
\hline \multirow{3}{*}{3} & Intact & 0 & 0 & \multirow{3}{*}{$\mathrm{O}$} \\
\hline & Cross & 50 & 8 & \\
\hline & Damage & 100 & 16 & \\
\hline \multirow{3}{*}{4} & Intact & 0 & 0 & \multirow{3}{*}{$\mathrm{O}$} \\
\hline & Cross & 50 & 3 & \\
\hline & Damage & 80 & 11 & \\
\hline \multirow{3}{*}{5} & Intact & 0 & 0 & \multirow{3}{*}{$\mathrm{O}$} \\
\hline & Cross & 38 & 2 & \\
\hline & Damage & 100 & 13 & \\
\hline \multirow{3}{*}{6} & Intact & 7 & 0 & \multirow{3}{*}{$\mathrm{O}$} \\
\hline & Cross & 31 & 1 & \\
\hline & Damage & 100 & 8 & \\
\hline
\end{tabular}

*Note: O: successful; $\Delta$ : unconfirmed; $\times$ : failed.

\subsection{Damage Localization}

Also, the damage localization utilizing MTS on NDI is investigated. Similar to Section 4.1, two-sensor sets including Sets $7 \mathrm{~A}$ to $7 \mathrm{~J}, 7 \mathrm{~B}_{\mathrm{L}}, 7 \mathrm{~B}_{\mathrm{R}}, 7 \mathrm{C}_{\mathrm{L}}$ and $7 \mathrm{C}_{\mathrm{R}}$ are taken into consideration. Fig. 17(a) shows the ratios and means of MD over threshold calculated with NDI of Sets 7A, 7B, $7 B_{R}$, 7C $\mathrm{C}_{\mathrm{L}}, 7 \mathrm{C}_{\mathrm{R}}$, and 7D to 7J (adjacent-sensor sets) as variables, while Fig. 17(b) shows those of Sets 7A to $7 \mathrm{~J}$ (adjacent-nodal-sensor sets) as variables. Although damage detection is generally successful, with a MD larger for damage condition than for cross validation, damage localization is still difficult because both ratios and means of MD over threshold show no clear indication of the sensor sets around the artificial damage. The only figure offering clearer indication is the bottom one of Fig. 17(a), i.e., the means of MD over threshold with NDI of adjacent-sensor sets, where the maximum occurs at Set $C_{L}$, closest to the artificial damage. Apart from this figure, other figures offer either false indications, e.g. maximum at sets far from the artificial damage, or confusing results, e.g. maximum at multiple sets. The effect of vehicle speed on the damage localization results is also

Formatted: Font color: Auto

Formatted: Font color: Auto 
investigated. Like the observations in Section 4.1.5, no clear effect was observed (results not shown here).

In summary, bridge damage detection can be achieved by performing MTS on NDIs of most sets of measurement points. This approach has several advantages: (1) no subjective decision is required in calculating NDI thus potential human errors can be prevented and an automatic detection task can be achieved; (2) high sensitivity of the statistical pattern of NDI to damage; (3) flexible choice of sets of measurement points.
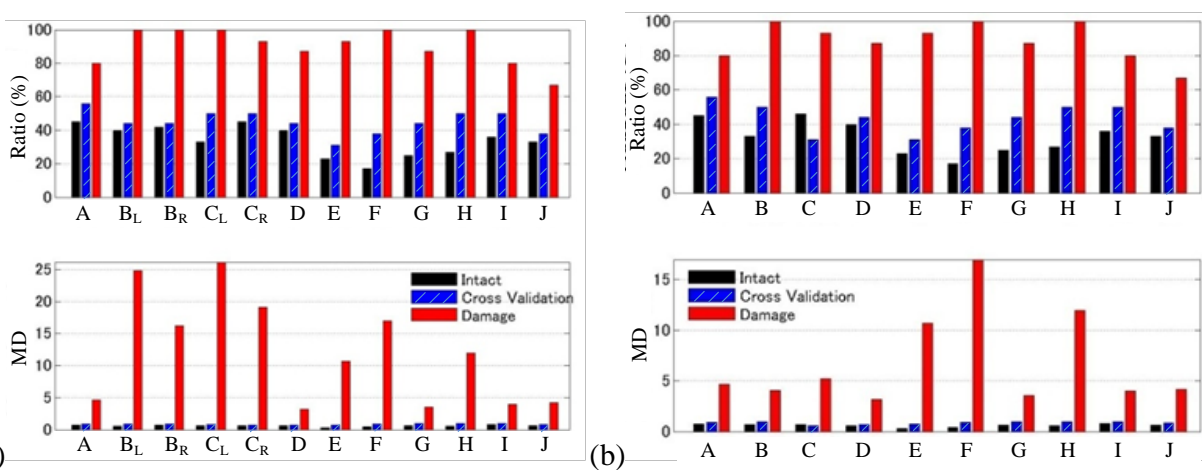

(a)

(b)

Fig. 17 Ratios (top) and means (bottom) of MD over threshold calculated with NDI of (a) Sets 7A, $7 \mathrm{~B}_{\mathrm{L}}, 7 \mathrm{~B}_{\mathrm{R}}, 7 \mathrm{C}_{\mathrm{L}}, 7 \mathrm{C}_{\mathrm{R}}$, and $7 \mathrm{D}$ to $7 \mathrm{~J}$ and (b) Sets $7 \mathrm{~A}$ to $7 \mathrm{~J}$ as variables. (Case V4)

\subsection{Concluding Remarks}

In this study, a field experiment was conducted on a real continuous steel Gerber-truss bridge with artificial damage applied in order to investigate bridge damage detection utilizing traffic-induced vibrations. The sensitivities to bridge damage of the identified modal parameters and their statistical patterns, Nair's damage indicator (NDI) and its statistical pattern, and different sets of measurement points to the bridge damage were studied. Several concluding remarks can be drawn as follows.

For the modal parameters, bridge damage detection was difficult to achieve by studying their changes using basic statistics. Although it can be achieved by performing MTS on certain modal parameters of certain sets of measurement points, two main difficulties were faced: the subjective selection of meaningful bridge modes and the low sensitivity of the statistical pattern of modal parameters to damage. 
For NDI, bridge damage detection can be achieved by performing MTS on NDIs of most sets of measurement points. As a damage indicator, NDI was superior to modal parameters, with the advantages of (1) no subjective decision is required in calculating NDI preventing potential human errors and enabling an automatic detection task to be implemented, (2) high sensitivity of its statistical pattern to damage, and (3) flexible choice of sets of measurement points considered herein.

While these concluding remarks apply to bridge structures and damage scenarios similar to those in this experimental study, the approaches presented in this paper show potential for further real world implementation. Further field testing on various real bridges with damage scenarios would support the general applicability of such approaches.

\subsection{Acknowledgement}

This study is partly sponsored by JSPS, Grant-in-Aid for Scientific Research (B) under project No. 24360178. The second author, K.C. Chang, is sponsored by "The JSPS Postdoctoral Fellowship for Foreign Researchers” Program. Such financial aids are gratefully acknowledged. Moreover, the authors would like to thank Osaka Prefecture Government for providing the experiment bridge and their assistance in the field experiment.

\subsection{References}

[1] National Transportation Safety Board (2008), Collapse of I-35W Highway Bridge Minneapolis, Minnesota, August 1, 2007, Highway Accident Report NTSB/HAR-08/03, Washington, DC.

[2] Yamada, K. (2008), An advice from rupture into a diagonal member of Kisogawa bridge, JSCE Magazine Civil Engineering, 93(1), 29-30. (in Japanese)

[3] Salawu, O.S. (1997), Detection of structural damage through changes in frequency: A review, Engineering Structures, 19,791-808.

[4] Doebling, S.W., Farrar, C.R., Prime, M.B. and Shevitz, D.W. (1998), A review of damage identification methods that examine changes in dynamic properties, Shock and Vibration Digest, 30(2), 91-105.

[5] Wang, Z. and Fang, T. (1986), A time-domain method for identifying model parameters, Journal of Applied Mechanics, ASME, 53(3), 28-32.

[6] Pandy, A.K., Biswas, M. and Samman, M.M. (1991), Damage detection from changes in curvature model shape, Journal of Sound and Vibration, 145, 321-332.

[7] Pandy, A.K. and Biswas, M. (1994), Damage detection in structures using changes in flexibility, Journal of Sound and Vibration, 169, 3-17. 
[8] He, X. and De Roeck, G. (1997), System identification of mechanical structures by a high-order multivariate autoregressive model, Computers and Structures, 64(1-4), 341-351.

[9] Abdel Wahab, M.M. and De Roeck, G. (1999), Damage detection in bridges using modal curvature: Application to a real damage scenario. Journal of Sound and Vibration, 226, 217-235.

[10] Brinker, R., Zhang, L. and Andersen, P. (2000), Modal identification from ambient responses using frequency domain decomposition, Proceedings of the 18th International Modal Analysis Conference, 625-630.

[11] Peeters, B. and De Roeck, G. (2001), One-year monitoring of the Z24-Bridge: environmental effects versus damage events, Earthquake Engineering and Structural Dynamics, 30(2), 149-171.

[12] Ren, W.X. and De Roeck, G. (2002), Structural Damage Identification using Modal Data. II: Test Verification, Journal of Structural Engineering, 128(1), 96-104.

[13] Deraemaeker, A., Reynders, E., De Roeck, G. and Kullaa, J. (2007), Vibration-based structural health monitoring using output-only measurements under changing environment, Mechanical Systems and Signal Processing, 22(1), 34-56.

[14] Yang, Y.B. and Chang, K.C. (2009), Extracting the bridge frequencies indirectly from a passing vehicle: Parametric study, Engineering Structures, 31, 2448-2459.

[15] Dilena, M. and Morassi, A. (2011), Dynamic testing of damaged bridge, Mechanical Systems and Signal Processing, 25, 1485-1507.

[16] Kim, C. W., Kawatani, M., and Hao, J. (2012), Model parameter identification of short span bridges under a moving vehicle by means of multivariate AR model, Structure and Infrastructure Engineering, 8(5), 459-472.

[17] Zhu, X.Q. and Law, S.S. (2006), Wavelet-based crack identification of bridge beam from operational deflection time history,International Journal of Solids and Structures, 43, 2299-2317.

[18] Zhang, Q.W. (2007), Statistical damage identification for bridges using ambient vibration data, Computers and Structures, 85(7-8), 476-485.

[19] Kim, C.W. and Kawatani, M., (2008), Pseudo-static approach for damage identification of bridges based on coupling vibration with a moving vehicle, Structure and Infrastructure Engineering, 4(5), pp.371-379.

[20] Kim, C.W., Isemoto, R., Sugiura, K. and Kawatani, M. (2012), Structural diagnosis of bridges using traffic-induced vibration measurements, Proceedings of IABMAS2012, Bridge Maintenance, Safety, Management, Resilience and Sustainability, 423-430.

[21] Kim, C.W., Kawatani, M., and Kim, K.B.(2005), Three-dimensional dynamic analysis for bridge-vehicle interaction with roadway roughness, Computers and Structures, 83(19-20), 1627-1645. 
[22] Gersch, W., Nielsen, N.N. and Akaike, H. (1973), Maximum likelihood estimation of structural parameters from random vibration data, Journal of Sound and Vibration,31(3), 295-308.

[23] Shinozuka, M., Yun C.B. and Imai, H. (1982), Identification of linear structural dynamic systems, Journal ofthe Engineering Mechanics Division, ASCE, 108(6), 1371-1390.

[24] Hoshiya, M. \& Saito, E. (1984), Structural identification by extended Kalman filter, Journal of the Engineering Mechanics Division, ASCE, 110(12), 1757-1770.

[25] Nair, K.K., Kiremidjian, A.S. and Law, K.H. (2006), Time series-based damage detection and localization algorithm with application to the ASCE benchmark structure, Journal of Sound and Vibration, 291(1-2), 349-368.

[26] Kim, C.W., Isemoto, R., Sugiura, K. and Kawatani, M. (2013), Structural fault detection of bridges based on linear system and MTS method, Journal of JSCE, 1, 32-43.

[27] Taguchi, G., and Jugulum, R. (2000), New trends in multivariate diagnosis, Indian Journal of Statistics, 62(B), 233-248.

[28] Taguchi, G. and Jugulum, R. (2002), The Mahalanobis-Taguchi Strategy, John Wiley \& Sons, New York.

[29] Bishop, C. M. (2006), Pattern Recognition and Machine Learning, 32-33, Springer, New York.

[30] Ljung, L. (1999), System identification-Theory for the user, 2nd ed., PTR Prentice Hall, Upper Saddle River, M. J.

[31] Brincker, R., Zhang, L., and Andersen, P. (2000), Modal identification from ambient responses using frequency domain decomposition, Proceedings of the 18th International Modal Analysis Conference, 625-630.

[32] Allemang, R. J. and Brown, D. L. (2010), Chapter 21: Experimental modal analysis, In Piersol, A. G. and Paez, T. L. (ed.), Harris' Shock and Vibration Handbook, 6th edition, McGraw-Hill Companies, Inc., New York.

[33] Akaike, H. (1974), A new look at the statistical model identification, IEEE Transactions on Automatic Control, 19(6), 716-723.

[34] Chang, K.C., Kim, C.W. and Borijin, S. (2014), Varaibility in bridge frequency induced by a parked vehicle, Smart Structures and Systems, 13(5), 755-773.

[35] Van Overschee, P. and de Moor, B. (1996), Subspace Identification for Linear Systems: Theory Implementation - Applications, Kluwer Academic Publishers. 